Тезисы докладов III всесоюз. конф. по вопросам скифо-сарматской археологии. М., 1972. С. 144-148.

12. Вагнер Е.В. История изучения сарматских бронзовых зеркал // Вестник Волгоградского государственного университета. Серия 4: История. Регионоведение. Международные отношения. 2012. № 1 (21). С. 168-176.

13. Трейстер М.Ю. Стеклянные сосуды в «технике сердечника» из раннесарматских погребений Южного Приуралья // XVIII Уральское археологическое совещание: культурные области, археологические культуры, хронология: мат-лы XVIII Уральского археологического совещания. Уфа: Изд-во БГПУ, 2010. C. 249-252.

14. Федоров В.К. Ритуальная посуда для отправления культа сомы из центрального Филипповского кургана // Ювелирное искусство и материальная культура: тез. докл. IV коллоквиума в ГЭ. СПб.: Гос. Эрмитаж, 1997. С. 70-72.

15. Акишев А.К. Искусство и мифология саков. Алма-Ата: Наука, 1984. 176 с.

16. Королькова Е.Ф. Ритуальные чаши с зооморфным декором в культуре ранних кочевников. Археологический сборник Государственного Эрмитажа.
Вып. 36 / отв. ред. А.Ю. Алексеев. СПб.: Издательство Государственного Эрмитажа, 2003. С. 28-60.

17. Топорков А.Л. Символика и ритуальные функции предметов материальной культуры // Этнографическое изучение знаковых средств культуры: сб. статей / отв. ред. А.С. Мыльников. Л.: Наука, 1989. C. $89-101$.

18. Очир-Горяева М.А., Дворниченко В.В. Особенности расположения предметов узды в погребальных комплексах (по материалам могильника Кривая Лука) // Нижневолжский археологический вестник. 2006. № 8. С. 236-245.

19. Сокровища сарматских вождей (Материалы раскопок Филипповских курганов) / под общ. ред. Л.Т. Яблонского. Оренбург: Димур, 2008. 144 с.

20. Смирнов К.Ф. Сарматы на Илеке. М.: Наука, $1975.175 \mathrm{c}$.

21. Кадырбаев М.К. Курганные некрополи верховьев р. Илек // Древности Евразии в скифо-сарматское время. М.: Наука, 1984. С. 84-93.

Работа выполнена при финансовой поддержке Комитета науки Министерства образования и науки Республики Казахстан (ИРН проекта AP05131573).

\title{
A COMPLEX OF RITUAL OBJECTS FROM THE ELITE FEMALE BURIAL IN WESTERN KAZAKHSTAN
}

(C) 2018

\author{
Lukpanova Yana Amangeldyevna, senior researcherer of Archeology Department \\ West Kazakhstan Centre of History and Archeology (Uralsk, Republic of Kazakhstan)
}

Abstract. The paper discusses in detail the items from the female burial of mound 6, Taksai-1 burial site, located in the West Kazakhstan Region, Terektinsky District, near the village Dolinnoe. A complex architectural gravestone structure, an accompanying rite of burial with the use of fire, the presence of rich clothing with various decorations, a complex of specific objects found in the pit, testify to the special status of the buried. All archaeological materials from the central pit of mound 6 performed a certain role in the life of the early nomads, composing a complex of ritual things for performing special rites. The functional significance of all the artifacts identified in the grave emphasizes the relation of the buried to the priestly class. In scientific literature there is no consensus about the existence of the priesthood as a profession in ancient times, but the early nomads revered the cult of a woman - the ancestor, and the priestesses were guides, keepers of the fire, the Sun, revered the goddess responsible for fertility. The burials of rich priestesses are distinguished by their special pomp of funeral ritual, the presence of gold jewelry and the individual composition of the inventory. All these characteristics are traced in mound 6 of Taksai-1 burial, it is a cult monument confirming the existence of a special priestly status in a social organization of the nomadic society.

Keywords: Urals; Western Kazakhstan; Taksai; early Iron Age; barrow; ritual; priestess; burial; burial ground; bronze; burial rite; tradition; ritual complex; chamber; structure; reel; sacralization; tree of life; cult of Sun; rein; sacrifice; status; canine amulets; solar symbol.

\section{ОТКРЫТИЕ И СУДЬБА ДРЕВНЕГРЕЧЕСКОГО ПАПИРУСА ИЗ МАНГАЛИИ (РУМЫНИЯ)} (C) 2018

Яровой Евгений Васильевич, доктор исторических наук, заведующий кафедрой археологии, истории древнего мира и средних веков Московский государственньий областной университет (г. Москва, Российская Федерация)

Аннотащия. Более полутора веков на западном побережье Черного моря ведутся раскопки античных городов. Среди них особое место занимает дорийская колония Каллатис, основанная выходцами из Гераклеи Понтийской, наиболее вероятно, в VI веке до нашей эры. В настоящее время на ее территории находится румынский город Мангалия. В 1959 году здесь при раскопках античного кургана на эллинистическом могильнике было обнаружено неограбленное погребение в каменном саркофаге. В нем находился скелет взрослого человека с позолоченным бронзовым венком. У его руки лежал древнегреческий папирус плохой сохранности. Для его спасения и консервации был приглашен советский реставратор М. Александровский, который 
сумел сохранить раритет. По просьбе румынской стороны он вывез папирус для реставрации в Москву, где его следы затерялись. В 2001 году румынские археологи начали поиски папируса. После трех лет работы в музеях и библиотеках им удалось установить местонахождение остатков свитка. Оказалось, что они хранятся в Центре реставрации им. Грабаря в Москве. В результате переговоров, благодаря доброй воле российской стороны, удалось достигнуть соглашения о возвращении уникальной для Румынии находки на ее историческую родину.

Ключевые слова: папирус; лавровый венок; курган; саркофаг; колония; Каллатис; Гераклея Понтийская; Мангалия; Добруджа; Румыния; Москва; Музей археологии; Центр реставрации; Александровский; Паслару; Лесовой; Черное море; эллинистический могильник; орфический текст; консервация.

С середины прошлого столетия на западном побережье Черного моря ведутся археологические исследования античных городов. Среди них значительный интерес представляет древнегреческая колония

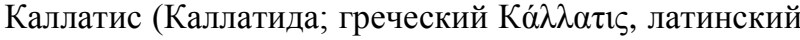
Callatis), расположенная на месте современного г. Мангалия близ г. Констанца в Румынии. Она была основана при македонском царе Аминте I (540-498 до нашей эры) или Аминте III (392-370 до нашей эры), выходцами из Гераклеи Понтийской, что находится на северном берегу Турции (современное поселение Эрегли). Несмотря на то, что подавляющая часть обнаруженных здесь археологических материалов датируются не ранее IV века до нашей эры, большинство исследователей считает, что с исторической точки зрения датой основания Каллатиса является VI век до нашей эры [1, р. 593-632; 2, р. 533589; 3, p. 1-50; 4, p. 38-39, 63-64].

Археологическое изучение Каллатиса и округи были начаты еще в конце XIX века. Спорадические исследования были предприняты археологом-любителем Д.С. Буткулеску в 1846-1916 годах [5, p. $903-$ 911] и инженером-топометристом П. Полоник (18581944 гг.) под научным руководством профессора Гр. Точилеску [3, p. 25-32]. В начале XX века Каллатис привлекает внимание профессиональных археологов. Так, в 1915 году основатель румынской археологии Василе Пырван создает музей археологии в Мангалии. С этого времени в античном городе начинаются систематические раскопки $[6$, р. 257-300; 7, p. $238-292 ; 8$, p. $17-55$; 9, p. $23-53 ; 10$, p. 329-339; 11 , p. 247-319; 12, p. 1-35].

За последние десятилетия здесь были сделаны интересные открытия, которые позволили более глубоко осмыслить результаты греческой, и в частности дорийской, колонизации Черноморского бассейна [2, p. $533-589 ; 13$, c. $5-250 ; 14$, c. $147-156 ; 15$, c. $15-36$; 16 , p. $155-176 ; 17$, p. $53-56 ; 18$, p. $97-108 ; 19$, p. 39 48; 20, p. 413-418 и др.]. Но среди открытий XX века особое место занимает уникальная находка античного папируса, обнаруженная во время раскопок древнегреческого кургана в центре Мангалии [21, р. 439 $445 ; 22$, р. 12-68]. История его открытия и дальнейшая судьба напоминают археологический детектив и заслуживают отдельного внимания.

В 1959 году в Румынской Добрудже началась грандиозная социалистическая стройка - создание современной курортной инфраструктуры на побережье Черного моря. Во время работ по закладке стадиона в Мангалии рабочие неожиданно наткнулись на эллинистический некрополь и срочно вызвали на стройплощадку археологов. Здесь оказалось множество античных захоронений с разнообразным инвентарем [23, p. 275-303; 24, p. 241-250; 25, p. 157-172]. Но даже на их фоне выделялся огромный античный курган, возведенный над погребением в саркофаге.
Первоначально был зафиксирован круг из каменных блоков диаметром 13,55-14,20 м. В его середине была прямоугольная яма, размерами $3,90 \times 2,25$ м. В ней обнаружили четыре сосуда [21, p. 445-446]. На глубине около 1,5 м от уровня каменного кольца показался саркофаг из больших каменных блоков, обработанных только с внутренних сторон. Он был перекрыт тремя большими плитами известняка. На них лежали фрагменты позолоченного венка из бронзовых листьев, имитировавших лавр, и остатки скорлупы от яиц.

В неограбленном саркофаге находился скелет человека, череп которого украшал венок, аналогичный найденному на перекрытии. В погребении сохранились остатки одежды, обуви и зерна пшеницы. Между костями правой руки и тазом погребенного был обнаружен свернутый в трубочку папирусный свиток размерами 30 / 5 см. [21, p. 447].

Вот как об этом открытии написал известный ученый-археолог и писатель Георгий Борисович Фёдоров, волею судьбы ставший участником эпопеи с папирусом: «В круглом склепе лежал скелет человека с золотым лавровым венком на черепе и папирусом в правой руке. Папирус был испещрен письменами. Судя по амфорам, которые находились в склепе, папирус и весь этот комплекс датируются IVIII веками до нашей эры. Когда один из ученых дотронулся до отслоившегося кусочка папируса, тот мгновенно превратился в прах. Археологи быстро покинули склеп, тщательно закрыли вход досками, камнями, завалили землей» [26, с. 325].

Размеры кургана и обнаруженные находки свидетельствовали о том, что в нем было найдено необычное захоронение. Хорошо известно, что в античную эпоху существовала красивая традиция, связанная с венками из сельдерея, лавра, дуба и других растений. Так, например, дубовыми венками венчали головы полководцев после победоносного завершения войн, а венки из листьев лавра дарили римским императорам при проведении триумфальных торжеств. В Древней Греции венками награждали победителей спортивных игр. А обычные венки из различных растений эллины надевали во время дружеских застолий - так называемых симпосионов. Традиция культа лавра нашла свое выражение и в том, что победитель состязания поэтов также получал в качестве награды лавровый венок (отсюда слово «лауреат») [27, c. 304].

На крышке и в самом саркофаге из Мангалии было найдено два венка из позолоченной бронзы, имитирующих листья лавра. То есть очевидно, что статус усопшего был крайне высоким. Данный курган представлял собой настолько уникальный комплекс, что после его открытия по инициативе Академии наук Румынии и Музея Национальной истории и археологии Констанцы было принято решение о строи- 
тельстве на его месте здания Музея археологии «Каллатис», включившее в себя курган с данным погребением.

Безусловно, среди находок этого комплекса самой выдающейся является папирус. Основываясь на обнаруженных археологических материалах, включая две македонские монеты Филиппа II и Александра Великого, свиток был датирован второй половиной IV века до нашей эры [3, с. 27]. Таким образом, его возраст более двух тысяч лет.

Находка папируса стала самым большим сюрпризом для археологов, и было решено сделать все возможное для его спасения. Однако румынские учёные вскоре поняли, что сами не в состоянии решить вопрос сохранения уникального свитка.

После обсуждения в Институте археологии им. В. Пырвана в Бухаресте было принято решение пригласить специалиста из Советского Союза. С просьбой о помощи обратились к хорошо известному в Румынии археологу Г.Б. Фёдорову, который оперативно связался с главным реставратором Музея изобразительных искусств имени Пушкина Михаилом Александровским. Узнав об открытии, тот сразу же согласился на предложение о помощи и незамедлительно вылетел в Мангалию. По свидетельству участников событий, М. Александровскому оформили паспорт и визу в течение одного дня, что явилось исключительным прецедентом в те времена. Утверждают даже, что за ним прислали специальный самолет. Легенда это или нет, трудно сказать. Во всяком случае, в отчете о своей командировке в Румынию М. Александровский ничего об этом не сообщает (Архив ГМИИ им. А.С. Пушкина).

По приезде в Мангалию он отправился на раскопки, где сразу же спустился в саркофаг. Сидя на корточках, М. Александровский проработал в узком и тесном пространстве четыре часа, пока не закончил консервацию уникальной находки. Когда же остатки свитка были собраны и аккуратно запакованы, он предложил передать их румынским коллегам. Однако в ответ услышал просьбу директора Института археологии Румынии Раду Вульпе забрать папирус в СССР для дальнейшей реставрации и консервации. Ему откровенно сообщили, что в стране в данный момент нет возможности сохранить эту хрупкую находку. С тех пор в Румынии никто не пытался выяснить ее дальнейшую судьбу. Судя по степени сохранности, румынские археологи не очень верили в успех консервации папируса.

Вместе с тем значение этой находки трудно переоценить. Достаточно лишь сказать, что свиток из Мангалии являлся первым и на тот момент единственным письменным источником, обнаруженным в Европе за весь XX век. Если не считать фрагментов папируса, найденных в 1962 году при раскопках в Дервени, близ города Салоники в Греции [28, с. 118 139; 29, p. 117-135; 30, p. 5-430], то открытий, равных мангальскому, в Европе не известно по сей день. Обычно папирусы находят на Ближнем Востоке и в Египте, где климат благоприятствует его сохранению, а для европейских широт подобное - огромная и исключительная редкость.

Поэтому не удивительно, что в 2001 году сотрудник Археологического музея «Каллатис», археологэксперт Ион Пыслару начал собственное расследо- вание по установлению судьбы «пропавшей» находки. В Румынии это открытие не было забыто и упоминания о нем часто встречаются в археологической литературе. Кроме того, информация о папирусе была хорошо известна не только археологическому сообществу, но и широкой общественности. В Румынии и в других странах даже сложилось мнение, что уникальный папирус бесследно исчез в Москве, куда его в 1959 году отправили на реставрацию. А это уже грозило и определенными политическими издержками.

И. Пыслару начал поиски папируса с работы в библиотеках и архивах. Почти три года он писал письма в различные организации, читал книги и изучал прессу прошлого века, наладил постоянную связь с российскими археологами и реставраторами. Через Академию наук и Министерство иностранных дел Румынии удалось подготовить многочисленные запросы в Россию. В результате этой незаметной, но очень важной работы ученый установил, что папирус из Мангалии был в Москве отреставрирован, законсервирован, но так и не прочтен. Его судьба была неясной. Поэтому появилась идея разыскать и вернуть уникальную находку.

Получив одобрение руководства Музея «Каллатис», И. Пыслару несколько раз посетил Москву, где побывал в Третьяковской галерее, Московском государственном университете (МГУ), Московском государственном областном университете (МГОУ), Государственном музее изобразительных искусств (ГМИИ) имени Пушкина. В результате поисков удалось познакомиться с главным хранителем Пушкинского музея Татьяной Потаповой, которая разрешила румынскому исследователю изучить этот вопрос в архиве учреждения. Целую неделю он работал в архиве и в результате нашел множество интереснейших документов, связанных с работой реставратора. Одновременно он пересмотрел множество газет в Ленинской библиотеке в надежде найти оперативную информацию об уникальной находке. И эти поиски увенчались удачей. И. Пыслару обнаружил публикацию под названием «Возвращенные к жизни» за 1962 год, в которой упоминался М. Александровский. В частности, в ней говорилось, что он завершил работу над папирусом, выполнив сложную реставрацию. Однако в другой заметке сообщалось, что свиток уже возвратили в Румынию. Эта информация вызывала вопросы: папируса в Румынии не было! Тем не менее было понятно, что поиски находятся на верном пути. Но надежда на то, что папирус сохранился, была призрачной.

Собрав все известные публикации, И. Паслару пришел к директору Центра реставрации им. Грабаря Александру Лесовому. Ему удалось установить, что когда-то папирус находился именно в этом учреждении. Здесь его заверили, что московские реставраторы постараются отыскать хоть какие-то документы, связанные с данным артефактом. Однако год назад в здании на улице Радио, где находился Центр, произошел крупный пожар, и шансов на успех поисков практически не осталось. Но в данной ситуации свою роль сыграл счастливый случай и профессионализм московских реставраторов.

Спустя две недели после посещения Центра реставрации в Музее «Каллатис» в Мангалии получили 
короткое сообщение от А. Лесового: «Всё, что вы искали, - у нас». На вопрос: «А что значит - всё?!»был получен такой же лаконичный ответ: «Всё!». Ситуацию прояснил телефонный разговор. Оказалось, что случилось то, на что уже никто не надеялся: в Центре реставрации был обнаружен не только папирус, но и все связанные с ним документы. В Мангалии не могли в это поверить! Удивляло и то, что после беседы А. Лесового с министром культуры РФ российская сторона не выдвигала никаких требований и готова была безвозмездно передать уникальный источник.

Вскоре румынская делегация из Мангалии прибыла в Москву. Ее возглавил директор Музея археологии «Каллатис», доктор Сорин Колеснюк. В процессе общения с российскими специалистами выяснился интересный факт. Оказалось, что еще в 1960-х годах прошлого столетия М. Александровский после завершения кропотливой работы собственноручно составил акт о возврате манускрипта в Румынию. Однако по непонятной причине это предложение осталось без внимания со стороны румынских коллег, и папирус на долгие годы остался в запасниках Центра реставрации.

Спустя десятилетия, 10 июля 2011 года, в Центре реставрации имени Грабаря в Москве все фрагменты папируса в трех специальных коробочках были переданы румынской делегации во главе с и.о. посла Румынии в РФ Василе Жоровяну. Российским реставраторам удалось установить, что древнегреческий текст был написан водостойкими чернилами. Вместе с папирусом был передан и диск с его подробным описанием и данными, полученными в результате просвечивания манускрипта ультрафиолетовыми и инфракрасными лучами. Однако, несмотря на то что местами видны отдельные буквы и их фрагменты, прочесть запись пока не удается. Тем не менее исследователи полагают, что в результате работы с новыми компьютерными программами, позволяющими совместить кусочки текста, существует вероятность разобрать хотя бы несколько слов. Если им это удастся - это будет фантастической удачей, которая позволит выяснить содержание рукописи. А по этому поводу высказываются самые разные гипотезы.

Например, существует версия, что на папирусе записаны так называемые орфические тексты, в которых Орфей взывает к богам Олимпа о возвращении его возлюбленной Эвридики. Но самая большая загадка: кто же был погребен в античной Каллатиде? Пока она остается без ответа. Однако остались предметы из погребения, фотографии и документы из раскопок 1959 года. Значит, попытки решить этот вопрос еще будут предприниматься.

Известно, что в Каллатисе в древности было много учебных заведений. По некоторым сведениям, именно тут была открыта и Prima Academia - первая в истории академия. Эта древняя дорийская колония дала истории, как минимум, четырех великих граждан, имена которых дошли до нашего времени. Среди них выдающийся историк и географ Деметрий Каллатиан (III век до нашей эры), литератор, создатель биографического жанра в европейской литературе Сатирос Перипатетик (III в. до н.э.), ученый и грамматик Гераклид Лемб (середина II в. до н.э.) и Истрос из Каллатиса (III в. до н.э.), автор книги «О трагедии» [31, с. $20 ; 32$, с. 256-257; 33, р. 15-540]. Конечно, в Каллатисе жили и другие выдающиеся люди, но история сохранила лишь эти имена. Находка папируса однозначно указывает, что в саркофаге находился известный в городе поэт или ученый.

В настоящее время этот уникальный папирус можно увидеть в экспозиции Музея археологии «Каллатис». Он представляет собой 154 бесценных обрывка разного размера. Несмотря на свой внешний вид, они являются огромной научной ценностью, так как позволяют хотя бы частично восстановить этот письменный источник античности. Аналогичных документов в Европе крайне мало. История же папируса из Мангалии напоминает лихо закрученный детектив, который написала сама жизнь: неожиданное открытие, спасение, затем долгие годы забвения, многочисленные перемещения и даже пожар в Москве и наконец благополучное возвращение в родную Каллатиду. В счастливом завершении этой истории переплелись удача и профессионализм археологов Румынии и мастерство реставраторов России. Благодаря их энтузиазму и настойчивости папирус удалось спасти от неминуемой гибели, и теперь он занял свое законное место в культурном наследии страны. Возвращение древнего раритета стало в Румынии событием общенациональной важности и продемонстрировало пример плодотворного и успешного научного сотрудничества ученых Румынии и России.

\section{Список литературы:}

1. Avram A. Les territoires d'Histros et de Callatis // Problemi della chora coloniale dall'Occidente al Mar Nero. Atti del quarantesimo convegno di Studi sul Magna / ed. A. Stazio. Taranto, 2001. P. 593-632.

2. Avram A. Coloniile greceşti din Dobrogea // Istoria românilor. T. I. Editura enciclopedica. Bucureşti, 2001. 867 p.

3. Preda C. Callatis // Éditions «Meridiane». Bucureşti, 1963. $51 \mathrm{p}$.

4. Pippidi D.M. Greci nel Basso Danubio dall'eta arcaica alla conguista romana // Biblioteca storica dell'antichita. № 8. Milano, 1971. 342 p.

5. Barnea I. Descoperiri arheologice din epoca feudală la Mangalia // Materiale si cercetarii arheologice. Vol. 6. 1959. P. 903-911.

6. Teodorescu D.M. L'idifice romano - byzantin de Callatis // Dacia. 1963. Vol. 7. P. 257-300.

7. Tafrali O. La cite pontique de Callatis // Revue Archeologique. 1925. № 21. P. 238-292.

8. Tafrali O. La cite pontique de Callatis, Recherches et fouilles // Arta şi Arheologia. 1927. № 1. P. 17-55.

9. Tafrali O. Les tumuli de Callatis // Arta şi Arheologia, 1928. № 2. P. 23-53.

10. Vulpe R. Deux terres cuites grecques de Callatis // Dacia, № 5-6, 1935-1936. P. 329-339.

11. Sauciuc-Săveanu Th. Callatis // Dacia. 19351936. № 5-6. P. 247-319.

12. Sauciuc-Săveanu Th. Nouvelles recherches et fouilles archeologiques en Roumanie // Bulletin de la Section historique de l'Academie Roumaine. 1947. Vol. 28, № 1. P. 1-35.

13. Блаватская Т.В. Западно-понтийские города в VII-I вв. до н.э. М.: Наука, 1952. 264 с.

14. Павлов Е. Об основании дорийской колонии Каллатис // Kallatida, Editura «Callasprint», Mangalia, 2014. C. $147-156$. 
15. Федосеев Н. Каллатийцы на Босфоре // Kallatida, Editura «Callasprint», Mangalia, 2014. C. 15-36.

16. Georgescu V., Ionescu M. Cercetari perieghetice in teritoriul callatian // Studii si cercetari de istorie veche si arheologie. 1997. Vol. 48, № 2. P. 155-176.

17. Preda C., Georgescu N. Săpăturile de salvare de la Mangalia din 1972 - necropola callatiană din zona stadionului // Pontica. 1975. № 8. P. 53-56.

18. Preda C., Bârlădeanu E. Săpăturile arheologice de salvare din zona de SV (şantierul naval Mangalia) a Mangaliei // Pontica. 1979. Vol. 12. P. 97-108.

19. Saprykin S., Păslaru I. Noua inscripţia din Callatis în onoarea impăratului Augustus // Kallatida, Editura «Callasprint». Mangalia, 2014. P. 39-48.

20. Păslaru I., Colesniuc S. O friză cu reprezentări de divinităti descoperită la Callatis // Pontica. 2004-2005. № 37-38. P. 413-418.

21. Preda C., Popescu Em., Diaconu P. Săpăturile arheologice de la Mangalia // Materiale si Crecetari Arheologice. 1962. № 8. P. 439-458.

22. Colesniuc S., Istoria singurului papirus descoperit in Romania // Editura «Callasprint». Mangalia, 2013. 78 p.

23. Preda C. Archaeological discoveries in the Greek cemetery of Callatis-Mangalia // Dacia. Noua Serie. 1961. Vol. V. P. 275-303.
24. Preda C., Tezaurul de la Mangalia // Studii si cercetari de istorie veche. 1961. № 12. P. 241-250.

25. Preda C. Una tomba con volta scoperta presso Mangalia - Callatis // Dacia. Noua Serie. 1962. № 6. Р. 157-172.

26. Федоров Г.Б. Дневная поверхность. М., 1966. $384 \mathrm{c}$.

27. Словарь античности. М.: Прогресс, 1989. $704 \mathrm{c}$.

28. Жмудь Л.Я. Орфический папирус из Дервени // Вестник древней истории. 1983. № 2. С. 118-139.

29. Most G.W. The Fire Next Time. Cosmology, Allegories, and Salvation in the Derveni Papyrus // Journal of Hellenic Studies. 1997. № 117. P. 117-135.

30. Betegh G. The Derveni Papyrus: Cosmology, Theology and Interpretation // Cambridge University Press, Cambridge, 2004. 456 p.

31. Страбон. География в 17 книгах. М.: ОлмаПресc, 2004. 638 c.

32. Солопова М.А. Гераклид Лемб // Античная философия: Энциклопедический словарь. М.: Прогресс-Традиция, 2008. 896 с.

33. Schorn S. Satyros aus Kallatis: Sammlung der Frauugmente mit Kommentar. Basel: Schwabe, 2004. 544 p.

\section{THE RETURN OF THE ANCIENT PAPYRUS: THE DISCOVERY AND FATE OF THE ANCIENT GREEK PAPYRUS FROM MANGALIA (ROMANIA)}

(C) 2018

Yarovoy Evgeny Vasilyevich, doctor of historical sciences, head of Archeology, History of the Ancient World and Middle Ages Department Moscow Region State University (Moscow, Russian Federation)

Abstract. On the west coast of the Black sea excavations of ancient cities have been conducted for more than a century and a half. Among them, a special place is considered to be the Dorian colony of Kallatis, founded by immigrants from Heraclea of Pontius, most likely in the VI century BC. Currently on its territory there is a Romanian city of Mangalia. In 1959, during the excavations of the ancient mound on the Hellenistic burial ground, an ungraded burial in a stone sarcophagus was discovered. It was a backbone of an adult with a gilded bronze wreath. Near his hands there was an ancient Greek papyrus. For his conservation a Soviet restorer M. Alexander was invited, he managed to preserve the rarity. At the request of the Romanian side, he took the papyrus for restoration to Moscow, where his traces were lost. In 2001, Romanian archaeologists began searching for the papyrus. After three years of work in museums and libraries, they were able to locate the rest of the scroll. It turned out that they are stored in the Center of restoration "Grabar» in Moscow. As a result of the negotiations, thanks to the good will of the Russian side, it was possible to reach an agreement on the return of a unique discovery for Romania to its historical homeland.

Keywords: papyrus; laurel wreath; mound; sarcophagus; colony; Kallatis; Mangalia; Heracleia of Pontius; Dobrudzha; Romania; Moscow; Museum of archeology; Restoration Center; Alexandrovsky; Paslaru; Lesovoy; Black sea; Hellenistic burial ground; Orphic text; conservation.

\section{ЭТНИЧЕСКИЕ И АДМИНИСТРАТИВНЫЕ ГРАНИЦЫ: ОТ КОНФЛИКТНОСТИ К СТАБИЛЬНОСТИ (НА ПРИМЕРЕ ОРЕНБУРЖЬЯ ХVIII-XIX ВЕКОВ)} (C) 2018

Федорова Алла Владимировна, доктор исторических наук, профессор кафедры истории и философии Оренбургский государственный аграрный университет (2. Оренбург, Российская Федерация)

Аннотация. Осмысление исторического опыта взаимоотношений народов затрагивает политическую, экономическую и культурную сферы жизни людей. Этнокультурный и межконфессиональный диалог в полиэтническом пространстве постоянно находится в центре внимания исследователей. За последние два с половиной столетия в разных регионах бывшего СССР и за рубежом было опубликовано более 50 тыс. научных работ, посвященных истории Казахстана дореволюционного периода. Историки России и Казахстана, используя обширную документальную базу, изучают все стороны взаимодействия своих народов. Попрежнему предметом обсуждения является многогранная проблема российско-казахских отношений, в част- 